\title{
Effectiveness of $0.2 \%$ chlorhexidine and oral routine care in terms of oral health status and oral microbiological colony count of self care deficit clients, Experimental study
}

\author{
Neelam Kumari ${ }^{1}$, Ms. Vinay Kumari ${ }^{2}$, Dr. Varsha A. Singh ${ }^{3}$, Dr. Shalu \\ Chandna $^{4}$ \\ ${ }^{\text {I}(M e d i c a l ~ S u r g i c a l ~ N u r s i n g, ~ M a h a r i s h i ~ M a r k a n d e s h w a r ~ C o l l e g e ~ o f ~ N u r s i n g / ~ M a h a r i s h i ~ M a r k a n d e s h w a r ~}$ \\ University, India) \\ ${ }^{2}$ (Medical Surgical Nursing, Maharishi Markandeshwar College of Nursing/Maharishi Markandeshwar \\ University, India) \\ ${ }^{3}$ (Microbiology, Maharishi Markandeshwar University, India) \\ ${ }^{4}$ (Dental, MM College of Dental Sciences and Research/Maharishi Markandeshwar University, India)
}

\begin{abstract}
Oral care is a vital component of holistic nursing in hospitalized patients and its provision influences the overall wellbeing of patients. Aim: To compare the effectiveness of $0.2 \%$ chlorhexidine and oral routine care in terms of oral health status and oral microbiological colony count of self care deficit clients. Setting and Design: Maharishi Markandeshwar Institute of Medical Sciences and Research (MMIMS\&R) Hospital Mullana Ambala. A true experimental, pre test- post test control group design was used. Method and material: Sixty self care deficit clients were selected using purposive sampling technique and were randomly assigned to experimental (0.2\% chlorhexidine) and control group (oral routine care) by using lottery method. The data was collected by "modified Beck oral assessment scale" and "oral microbiological colony count recording sheet". Statistical Analysis Used: The data were analyzed using chi-square, paired t-test and unpaired t-test. Results: The finding of the study indicated that both the groups (experimental and control group) were homogenous before administering oral care. After administering oral care, the mean oral health status score was significantly lower in experimental group than control group (6.10 versus 11.57; ' $t$ ' $=8.90$; $d f=58 ; p=0.001)$. The mean oral microbiological colony count of Candida (50.93 versus 217.37 ), Moraxella Catarrhalis (44.70 versus 185.83 ), Alpha Hemolytic Streptococci (52.77 versus 183.80), Klebsilla (55.63 versus 178.10) and CoNS (64.5 versus 186.60$)$ was significantly lower in experimental group than control group ( $p$ <0.05). No significant association was found among levels of oral health status and levels of oral microbiological colony count with selected demographic and clinical variables. Conclusion: $0.2 \%$ chlorhexidine was more effective than oral routine care in improving oral health status and decreasing oral microbiological colony count among self care deficit clients.
\end{abstract}

Keywords: $0.2 \%$ Chlorhexidine oral care, Mircobiological colony count, Oral health status, Oral routine care, Self care deficit clients.

\section{Introduction}

Oral health is integral to general health and it should not be interpreted as separate entity. The oral flora of critically ill adults differs from that of healthy adults and contains organisms that can rapidly cause respiratory infections and pneumonia.

Many authors in their report further suggested that improving the oral hygiene of the critically ill will have a great impact on the occurrence of periodontal diseases. Although nurses recognize that oral hygiene is an integral part of care in intensive care units (ICUs).

Saline oral care is widely advocated in the nursing literature. Normal Saline is a sterile, nonpyrogenic solution for fluid and electrolyte replenishment. Chlorhexidine (CHX) is a cationic chlorophenyl bis-biguanide antiseptic agent. It has been used as an oral disinfectant in mechanically ventilated patients because of its ability to bind to oral tissues with subsequent slow release of antiseptic properties and therefore a long period of antibacterial action. $^{4}$

Aim of the study to compare oral health status and microbiological colony count of self care deficit clients after administration of $0.2 \% \mathrm{CHX}$ and oral routine care in experimental and control group. The conceptual framework of the study was developed by the investigator based on Bertanlanffy's General System Theory which consists of components like: Environment, Input, throughput, Output and Feedback. 


\section{Methods And Material"}

Inclusion criteria for the study Age $\geq 18$ years, Patients willing to participate, Patients expected to stay in hospital for $>48$ hours and exclusion criteria include Hypersensitivity to $0.2 \%$ chlorhexidine, Patients in whom oropharyngeal cleansing is contraindicated.

This study was approved by the institutional ethical committee. Administrative approval to conduct the study was taken from the principal of Maharishi Markandeshwar Medical College Mullana, Ambala. Consent form was prepared for the self care deficit clients. A true experimental pre test- post test control group design was used.

The purposive sampling technique was used to select the sample for study. Sample assignment done by random assignment (lottery method) on 60 self care deficit clients, where equal number of self care deficit clients were randomized to experimental (30 subjects) and control group (30 subjects).

\begin{tabular}{|l|l|l|l|}
\hline & DAY 1 & DAY 2 & nAY \\
\hline$R_{E}$ & $\mathrm{O}_{1} \mathrm{M}_{2} \mathrm{X}_{\mathrm{CHX}-\mathrm{M}} \mathrm{X}_{\mathrm{CHX}-\mathrm{E}}$ & $\mathrm{X}_{\mathrm{CHX}-\mathrm{M}} \mathrm{X}_{\mathrm{CHX}-\mathrm{E}}$ & $\mathrm{O}_{5} \mathrm{M}_{6}$ \\
\hline $\mathrm{R}_{\mathrm{C}}$ & $\mathrm{O}_{3} \mathrm{M}_{4} \mathrm{X}_{\mathrm{NS}-\mathrm{M}} \mathrm{X}_{\mathrm{NS}-\mathrm{E}}$ & $\mathrm{X}_{\text {NS-M }} \mathrm{X}_{\text {NS-E }}$ & $\mathrm{O}_{7} \mathrm{M}_{8}$ \\
\hline
\end{tabular}

Figure 1: Symbolic Representation of Research Design

\section{Symbolic Description:}

$\mathbf{O}_{1} \mathbf{M}_{2}$ - Oral Health Assessment Score and microbiological colony count of experimental group before providing oral care with $0.2 \%$ chlorhexidine.

$\mathbf{X}_{\mathbf{C H X}-\mathbf{M}} \mathbf{X}_{\mathbf{C H X - E}}$ - Oral Care with $0.2 \%$ chlorhexidine solution once in morning and evening in experimental group for consecutive 2 days.

$\mathbf{O}_{3} \mathbf{M}_{4}$ - Oral health Assessment Score and microbiological colony count of control group before providing oral care with normal saline.

$\mathbf{X}_{\text {NS-M }} \mathbf{X}_{\text {NS-E }}$-Oral Care with normal saline once in morning and evening in control group for consecutive 2 days.

$\mathbf{O}_{5} \mathbf{O}_{6}$ - Oral Health Assessment Score and microbiological colony count of experimental group after providing oral care with $0.2 \%$ chlorhexidine on $3^{\text {rd }}$ day.

$\mathbf{O}_{7} \mathbf{O}_{8}$ - Oral Health Assessment Score and microbiological colony count of control group after providing oral care with normal saline on $3^{\text {rd }}$ day.

The data collected from self care deficit clients admitted in medical, surgical, orthopedic units and ICU, ICCU, surgical ICU of Maharishi Markandeshwar Institute of Medical Sciences and Research (MMIMS\&R) Hospital, Mullana, Ambala. It is 780 bedded multispecialty tertiary Hospital.

Following tools were developed for data collection:

1. Demographic data sheet Performa

2. Clinical data sheet Performa

3. Oral assessment scale

4. Oral microbiological colony recording sheet

Demographic data sheet Performa was developed to gather demographic data and contained of 3 items i.e. age, gender and personal habits (i.e. smoking, Alcohol consumption, Tobacco chewing).

Clinical data sheet Performa was developed to gather clinical data of self care deficit clients contained of 6 items i.e. diagnosis, drugs prescribed, GCS score $(<8,9-12,>13)$, client with (i.e.Tracheotomy, Nasogastric tube, Central venous catheter, Ventilator and any other like cervical fracture, hand fracture etc), gag reflex and swallowing reflex.

Oral health assessment scale was comprised of 5 items and each includes four sub items, seeking information on oral health status. The Beck Oral Assessment Scale (BOAS) include assessment of lips, gingival/ oral mucosa, tongue, teeth and saliva. BOAS (Beck Oral Assessment Scale) primarily accomplished by Beck (1979) and Eilers et al., (1988) do not incorporated the microbial changes occurring in the mouth. Considering the relationship between microbial flora changes and oral health is an important element of oral health to measure in research.

Individual score on the BOAS ranges from 1-20; higher scores indicate poor oral status. The scores were categorized into:

$1-5=$ No dysfunction

6-10 = Mild dysfunction

11-15 = Moderate dysfunction

16-20 Severe dysfunction

Oral microbiological colony count recording sheet contain items regarding recording of microbial colony count before and after administering oral care. It is a count of normal commensals (CoNS, Alpha Hemolytic Streptococci) and pathogenic organisms (candida, Moraxella Catarralis\&Klebsiella) which are capable of 
growing in sample cultured over on blood agar before and after oral routine care and $0.2 \%$ chlorhexidine oral care.

Individual score on the Microbiological colony count can range from $<20->200$. The microbial colony count was categorized into:

1. Confluent Growth: $>200 \mathrm{CFU} / \mathrm{cm}^{3}$

2. Moderate Growth: $100-200 \mathrm{CFU} / \mathrm{cm}^{3}$

3. Moderate Scanty: 20-99 CFU/ $\mathrm{cm}^{3}$

4. Scanty Growth: $\quad<20 \mathrm{CFU} / \mathrm{cm}^{3}$

Reliability of oral assessment scale was assessed through inter-rater reliability and the reliability coefficient of oral health assessment scale was 0.98 (acceptable limit is 0.61 to 0.81). Researcher was trained and certificate had obtained from the Maharishi Markandeshwar Institute of Dental Sciences, Mullana, Ambala for the use of oral assessment scale. Study was conducted in the month of December, 2012 to January, 2013.

\section{Analysis And Interpretation Of Data"}

The data was analyzed and interpreted by employing descriptive and inferential statistics. SPSS version 17.0 was used to analyze the data. Level of significance for the present study was taken as $\mathrm{p} \leq 0.05$.

TABLE 1 Chi-square showing comparison of experimental and control group in terms of demographic variables

\begin{tabular}{|c|c|c|c|c|c|}
\hline \multirow[b]{2}{*}{ Sample characteristics } & \multirow[b]{2}{*}{$\begin{array}{c}\text { Experimental } \\
\text { group } \\
\mathbf{f}(\%) \\
\end{array}$} & \multirow[b]{2}{*}{$\begin{array}{c}\text { Control } \\
\text { group } \\
\mathrm{f}(\%)\end{array}$} & \multicolumn{3}{|c|}{$\mathrm{N}=60$} \\
\hline & & & $\begin{array}{c}\text { Chi/yate } \\
\text { s }\end{array}$ & df & p-value \\
\hline \multicolumn{6}{|l|}{ 1. Age (in year) } \\
\hline 1.1. $18-28$ & $07(23)$ & $03(10)$ & & & \\
\hline 1.2. $29-39$ & $02(7)$ & $03(10)$ & & & \\
\hline 1.3. $40-50$ & $07(23)$ & $09(30)$ & 0.96 & 3 & $0.81^{\mathrm{NS}}$ \\
\hline 1.4. $>51$ & $14(47)$ & $15(50)$ & & & \\
\hline 2. Gender & & & & & \\
\hline 2.1. Male & $19(63)$ & $20(67)$ & & & \\
\hline $\begin{array}{l}\text { 2.2. } \quad \text { Female } \\
\text { 3. } \text { Smoking }\end{array}$ & $11(37)$ & $10(33)$ & 0.07 & 1 & $0.78^{\mathrm{NS}}$ \\
\hline 3.1. Current & $10(33)$ & $13(43)$ & & & \\
\hline 3.2. Former & $06(20)$ & $03(10)$ & 0.65 & 2 & $0.72^{\mathrm{NS}}$ \\
\hline 3.3. Never & $14(47)$ & $14(47)$ & & & \\
\hline 4. $\begin{array}{l}\text { Alcohol } \\
\text { consumption }\end{array}$ & $00(0)$ & 01(3) & & & \\
\hline 4.1. Current & $02(7)$ & $02(7)$ & 0.25 & 2 & $0.88^{\mathrm{NS}}$ \\
\hline 4.2. Former & $28(93)$ & $27(90)$ & & & \\
\hline 4.3. Never & & & & & \\
\hline $\begin{array}{l}\text { 5. Tobacco chewing } \\
51 \text { Current }\end{array}$ & $02(7)$ & $05(17)$ & & & \\
\hline 5.2. Former & $01(3)$ & $00(0)$ & 1.59 & 2 & $0.74^{\mathrm{NS}}$ \\
\hline 5.3. Never & $27(90)$ & $25(83)$ & & & \\
\hline
\end{tabular}

$\chi^{2}(1)=3.84, \chi^{2}(2)=5.99, \chi^{2}(3)=7.82$

NS- not significant ( $\mathrm{p}>0.05)$

Thus both experimental and control group were homogenous and comparable in terms of demographic variables before administering oral care [Table 1].

TABLE 2Chi-square showing comparison of experimental and control group in terms of clinical variables

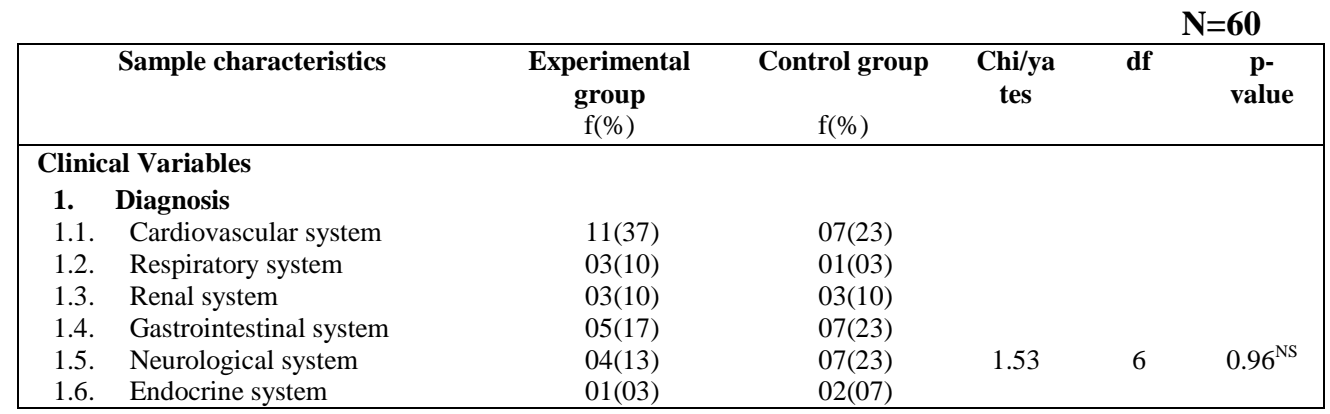




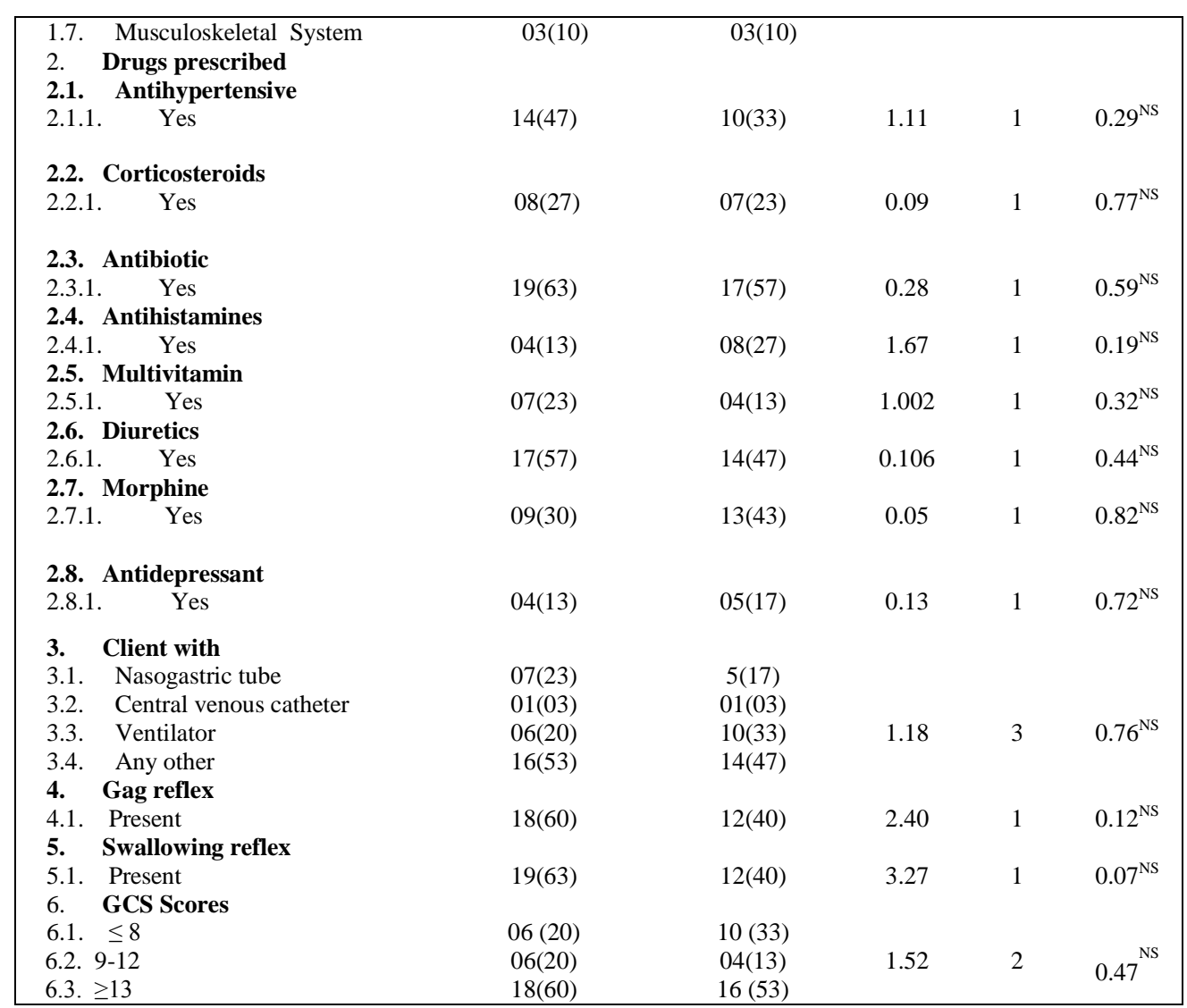

CVS- Cardiovascular system, GI= Gastrointestinal system, GCS= Glasgow coma scale $\chi^{2}(1)=3.84, \chi^{2}(2)=5.66, \chi^{2}(3)=7.82, \chi^{2}(6)=12.59$,

NS- not significant $(\mathrm{p}>0.05)$ Thus both experimental and control group were homogenous and comparable before administering oral care with respect to clinical variable [Table 2].

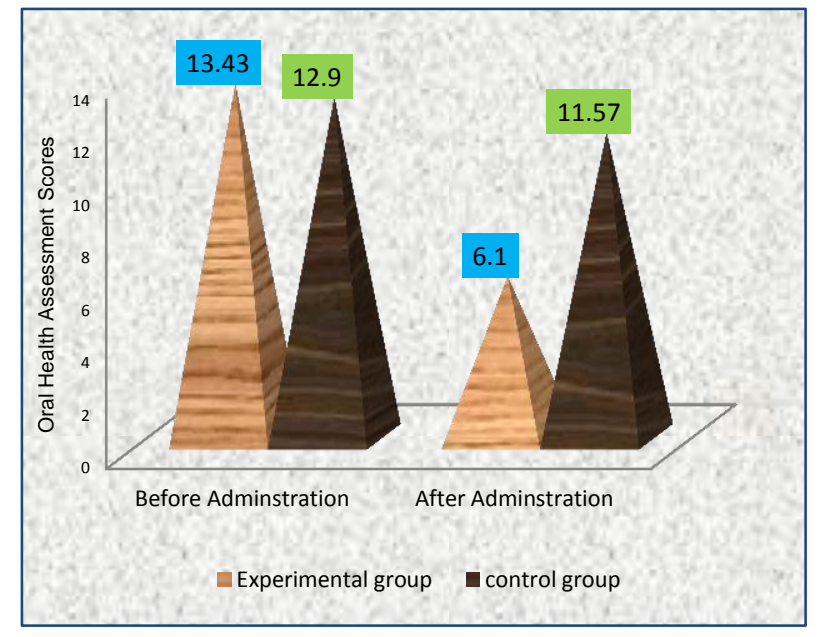

Figure 2: Cone diagram showing comparison of oral health assessment scores before and after providing oral care in terms of oral health status in experimental and control group.

In experimental group, mean oral health status score was 13.43 before providing oral care and declined to 6.10 after providing oral care. The computed ' $t$ ' value (' $t$ ' $=20.38, p=0.001)$ was found to be statistically significant at 0.05 level of significance.

In control group, mean oral health status score was 12.90 before providing oral care and declined to 11.57 after providing oral care. The computed ' $t$ ' value (' $t$ ' $=4.89, p=0.003$ ) was found to be statistically significant at 0.05 the level of significance. Thus there was significant reduction in oral health status scores of 
experimental and control group after providing oral care which shows that oral health status of self care deficit clients significantly improved after providing oral care shown in (figure 2).

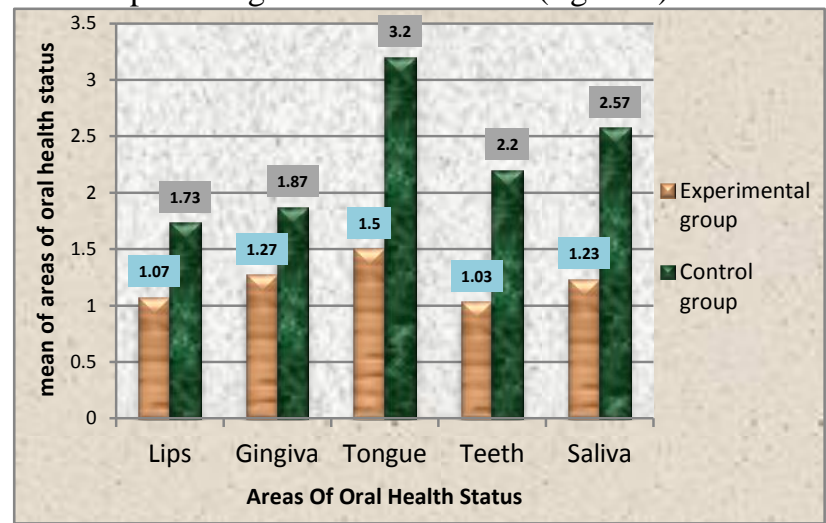

Figure 3: Bar diagram showing comparison of experimental and control group in terms of areas of oral health status after administering oral care.

Thus, there was significant difference in oral health status of experimental and control group in all the areas of oral health status after administering oral care. Therefore the oral care with $0.2 \%$ chlorhexidine was effective improving oral health status in all areas of oral health.

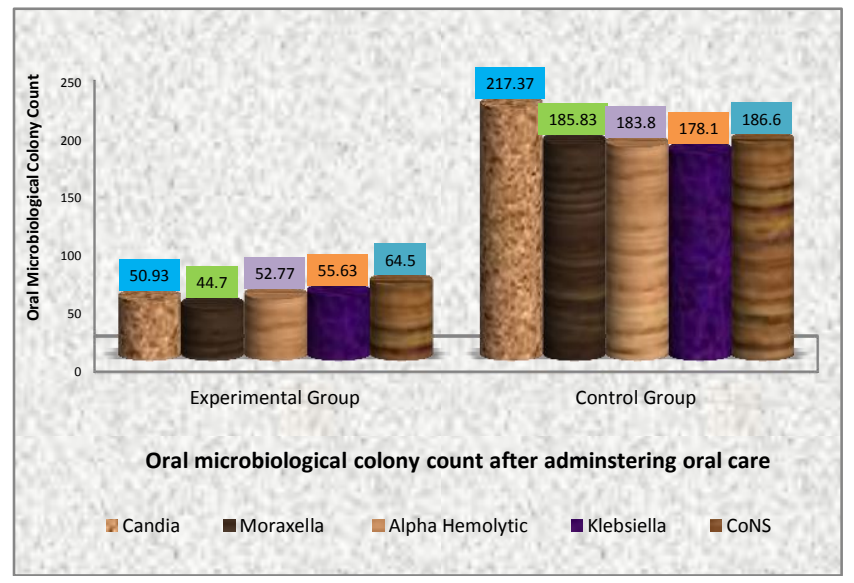

Figure 4:Cylindrical diagram showing comparison of experimental and control group after administration of oral care in terms of oral microbiological colony count

The mean oral bacteriological count of Candida (50.93 versus 217.37 ), Moraxella Catarrhalis (44.70 versus 185.83 ), Alpha Hemolytic Streptococci (52.77 versus 183.80), Klebsilla (55.63 versus 178.10) and CoNS (64.5 versus 186.60$)$ was significantly lower in experimental group than control group $(\mathrm{p}<0.05)$.

The study found that there was significant difference in experimental group and control group with respect of microbiological colony count of candida, moraxella, Alpha Hemolytic Streptococci, Klebsiella and CoNS after administering oral care. The microbiological colony count in experimental group was significantly lower than that of control group. Therefore, $0.2 \%$ chlorhexidine was more effective in reducing the microbiological colony count of Candida Albican, Moraxella Catarralis, Klebsiella, Alpha Hemolytic Streptococci and CoNS shown in (figure 4).

Study also found that the oral care with $0.2 \%$ chlorhexidine was effective in reducing oral microbiological colony count of Candida Albican, Moraxella Catarralis, Alpha Hemolytic Streptococci, Klebsiella and CoNS in experimental group rather than the oral care with normal saline was effective in reducing oral microbiological colony count of Moraxella Catarralis, Alpha Hemolytic Streptococci and CoNS but was not significantly effective in reducing Candida Albican and Klebsiella in control group.

\section{Discussion"}

Oral infections such as tooth decay and periodontal disease are perhaps the most common bacterial infections in critically ill clients. In the United States the annual cost for the symptomatic treatment of oral infections, about 24 billion dollars in 2006. 
In the present study, there was significant difference $(\mathrm{t}=8.90, \mathrm{p}=0.001)$ in oral health status in experimental $(6.10 \pm 0.80)$ and control group $(11.57 \pm 3.27)$ after administering $0.2 \%$ chlorhexidine and oral routine care. Similarly, Nancy J. Ames et al (2006) studied effects of systematic oral care with $0.2 \%$ chlorhexidine and normal saline in critically ill patients and found that scores on the Beck Scale differed significantly $(F=4.79, p=.01)$ in control group and the systematic oral care group. Unlike the control group, the treatment group had decreasing scores on the Beck Scale.

The results of this study show significant difference in experimental and control group in terms of all the areas including lips $(\mathrm{t}=3.88, \mathrm{p}=0.003)$, gingiva $(\mathrm{t}=3.39, \mathrm{p}=0.001)$, tongue $(\mathrm{t}=7.89, \mathrm{p}=0.001)$, teeth $(\mathrm{t}=6.78$, $\mathrm{p}=0.001)$ and saliva $(\mathrm{t}=6.67, \mathrm{p}=0.001)$ of oral health status after administering oral care. Similarly study done by A. H. Meckel, (2009) who studied the comparison of antibacterial mouthrinses: effects of chlorhexidine, phenolics, and sanguinarine on dental plaque and gingivitis and found that rinsing with $0.2 \%$ Chlorhexidine had significantly less gingivitis (31\% reduction), gingival bleeding (39\% reduction), and plaque (49\% reduction) and was significantly better than Normal saline and Sanguinarine oral rinse $(\mathrm{P}<0.05)$.In this study, $0.2 \%$ chlorhexidine oral care was effective in significantly reducing all oral microbes whereas oral routine care with normal saline was effective in reducing only 3 out of 5 microbes. This finding is consistent with the another study conducted by Mirelle Koeman et al (2010), concluded that $0.2 \%$ CHX oral care provided significant reduction in oropharyngeal colonization of both gram-negative and gram-positive microorganisms. ${ }^{[}$Another study done by F. Fourrier, (2009) studied the effect of dental plaque antiseptic decontamination of plaque colonization by aerobic nosocomial pathogens and nosocomial infections and found that an antiseptic decontamination of dental plaque with a $0.2 \%$ chlorhexidine oral care decreases dental bacterial colonization, and reduce the incidence of nosocomial infections in ICU patients. Similarly Bopp M (2006) who determined the effect of gingival and dental plaque antiseptic decontamination on nosocomial infections acquired in the intensive care unit and found that antiseptic decontamination with $0.2 \%$ chlorhexidine(two times a day) was significantly effective in experimental group than control group.

\section{Conclusion}

The findings of the this study revealed that, $0.2 \%$ CHX was more effective than oral routine care in improving oral health status and decreasing oral microbiological colony count in self care deficit clients. Therefore, it is recommended to use $0.2 \%$ chlorhexidine for maintaining oral hygiene in self care deficit clients.

\section{REFERENCES}

[1]. Ulman Almanda, " $0.2 \%$ chlorhexidine oral care in icu clients in terms of oral health status" http://eprints.qut.edu.au/31765/1/Amanda_Ullman_Thesis.pdf (Book style with paper title and editor)

[2]. Developing and implementing an oral care policy and assessment tool [internet] http://nursingstandard.rcnpublishing.co.uk/archive/ article

[3]. Morris Braham R, "Oral health and care in the intensive care unit: state of the science." Am J Crit Care 13(1), 2001: 25-33; discussion 34. (book style)

[4]. Tablan OC, "Guidelines for preventing health-care-associated pneumonia: recommendations of CDC and the Healthcare Infection Control Practices Advisory Committee" MMWR RecommRep. 2004;53(RR-3):1-36. http://www.guideline.gov. Accessed July 25, 2007. (Conference proceedings)

[5]. Feider LL, "Oral care practices for orally intubated critically ill adults" Am J Crit Care.2010; 19(2):175-183.

[6]. Albandar JM, "Global epidemiology of periodontal diseases: an overview" Periodontology 2002; 29:7-10.

[7]. Spence K, “Nursing management a systems approach, Philadelphia” W. B. Saunders Company, 2000;56-74

[8]. Ullman Amanda, "Oral health of critically ill clients" http://eprints.qut.edu.au/31765/1/Amanda_Ullman_Thesis.pdf

[9]. Becks, H, “dental caries: Prevention and prognosis" J. Am. Dent. Assoc. 2000;31:1189-1200. (book style)

[10]. Nancy J. Ames, “ Effects of Systematic Oral Care in Critically Ill Patients: A Multicenter Study” Am J Crit Care 2011;20:e103e114 (book style)

[11]. A. H. Meckel, “ The Long-Term Effect of a Mouthrinse with $0.2 \%$ chlorhexidine on Dental Plaque and Gingivitis: A Systematic Review" J ClinPeriodontol. 2009; 78:7, 1218-1228 (book style with review)

[12]. Fourrier F, "Effect of gingival and dental plaque antiseptic decontamination on nosocomial infections acquired in the intensive care unit: a double-blind placebo-controlled multicenter study" Crit Care Med. 2005;33(8):1728-1735. (book style)

[13]. Bopp M, “ Systematic literature review of oral hygiene practices for intensive care patients receiving mechanical ventilation" Am J Crit Care.2007;16(6):552-562 (book style) 